\title{
Fire safety systems in buildings-problems and concerns beyond the project
}

\begin{abstract}
Fire is one of the major concerns when analyzing the potential risks on buildings. To face undesired situations it is common to install fire safety systems in a way to prevent fire occurrence or to protect buildings against such events. In these cases it is usual to have well designed systems as well as good installation procedures. However the problem relies after this stage where it is needed some attention to issues related to test and maintenance that are not meet. This article states this problem presenting the risk of not identifying possible hidden failures that will prevent the safety barrier of having a successfully operation when it will be needed in a real fire situation. It is also shown the importance of having a test and maintenance planning and how to establish the frequency of those activities.
\end{abstract}

Keywords: fire safety, hidden failures, test maintenance availability
Volume 2 Issue 5 - 2017

\author{
Sobral $]^{1,2}$ \\ 'Department of Mechanical Engineering, Instituto Superior de \\ Engenharia de Lisboa, Portugal \\ ${ }^{2}$ Centre for Marine Technology and Ocean Engineering \\ (CENTEC), Universidade de Lisboa, Portugal
}

\section{Correspondence: José Sobral,}

MechanicalEngineeringDepartment, ISEL-Instituto Superior de Engenharia de Lisboa, Rua Conselheiro Emídio Navarro, I, Lisboa, Portugal, Tel +35/2/83/70I3,

Email jsobral@dem.isel.ipl.pt
Abbreviations: NFPA, national fire protection association; CEA, comité euro penne des assurances

\section{Introduction}

If we look at fire safety measures that are usually present in large buildings it is common to observe the existence of safety systems whatever active or passive or manually or automatically actuated. In fact, due to legislation imperatives or personal safety concerns these systems are installed to protect the building and its content (including people) of undesirable events related to fire occurrences.

Along the years some standards and regulations have been developed to assure a proper design, installation, maintenance and operation of such systems and avoid, limit or mitigate fire events. In this particular aspect a reference should be done to the National Fire Protection Association (NFPA) that has been for more than a century the leader on research and development of devices and on the publication of standards and regulation about fire safety. In Europe this role has been supported by the Comité Euro penne des Assurances (CEA).

Although all the standards and regulations produced, as well as the efforts towards finding effective physical solutions for equipment design and its correct implementation in buildings, it is very important to assure that all these safety barriers are properly installed and well maintained.

Usually these systems rely inactive for long periods or, in case of automatic systems, in a dormant mode. The so-called hidden failures are only often detected through periodic inspections or tests and thus it is very important to assure such procedures in a way to guarantee high fire safety levels. Concerning fire safety systems it is observed that equipment design and installation are not a problem. Based on this, it is important to pay attention to the remaining life time of such equipment and on their effective operation.

\section{Fire risk}

Fire risk assessment is the process in which the probability of an undesired event and the consequences of it are evaluated in a safety perspective. The correct adoption of safety measures will decrease risk. In this particular aspect, fire risk depends on all preventive and protective measures installed, affecting the probability of occurrence and the severity, respectively. However, it is fundamental to assure that these measures remain operational throughout the time. Related to this concern Fontana et al. ${ }^{1}$ refer a study carried out in Switzerland for a period of about 10 years reporting around 335000 fires in buildings. Only in Berna's canton occurred 1538 fires in industrial buildings corresponding to 45070million dollars in damage. Another study performed in the Great Britain ${ }^{2}$ refers that around 800 persons die and around 15000 are injured per year due to fire incidents. These and other testimonials are sufficient to understand the impact of fire safety and the existence of a fire risk assessment.

\section{The problem}

As previously stated, fire safety systems are usually well designed and properly installed. However the problem appears after this stage, where it is frequent to observe a complete disregarding for the accomplishment of maintenance and test planning. Dieken ${ }^{3}$ states that when facing a fire about one third of the safety systems do not work properly just because of the lack of inspection, test or maintenance of such systems. The author also refers that due to improper maintenance around $49 \%$ of the fire extinguishing systems installed failed causing property damages around 15.9 million dollars per year. Unfortunately, this type of hidden failures is only revealed when a fire occurs and the system is required.

\section{The solution}

As it can be understood the frequency of tests plays an important role on the building fire safety assurance. It is expected that the higher the frequency, the sooner hidden failures are revealed. Thus, the solution relies on establishing a maintenance and test planning and to assure its accomplishment. All critical items of the fire safety systems should be analyzed from the probability of failure and failure consequences point of view and must be tested and inspected to assure system's availability and successfully operation (reliability). 
If assuring the accomplishment of the test and maintenance planning of fire safety systems is somehow a decision of the management structure or building and facilities managers, the establishment of the frequency for those activities is commonly the subject of discussion although some recommendations pointed out by regulators or insurance companies.

Theoretically the critical items are non-repairable and based on that their probability of failure at time " $t$ " (or its cumulative probability of failure) assumes the same value of the instantaneous unavailability.

As reported and detailed by Sobral \& Ferreira ${ }^{4}$ the average unavailability $(\mathrm{Q}(\mathrm{t}))$ of an item is dependent on the frequency of inspection $(\tau)$ and on its failure rate $(\lambda)$, according to the following expression:

$$
Q(t)=1-\frac{\left(1-e^{-\lambda . \tau}\right)}{\lambda . \tau}
$$

Hauptmanns et al. ${ }^{5}$ used an identical expression to determine the average unavailability of a sprinkler system \& $\mathrm{Zio}^{6}$ also presents a detailed study about this issue reaching a similar expression. By simulating test intervals or frequency of inspection $(\lambda)$ it is possible to determine the average unavailability of the items and based on that and on the system configuration and arrangement it is possible to estimate the probability of failure when a demand occurs on the system. Thus, the maintenance and test planning can be established and supported by a scientific basis.

\section{Conclusion}

In my opinion there must be awareness for the situation reported in this article concerning fire safety systems installed in buildings. People must know that these systems are usually inactive or in a dormant state and could have significant hidden failures that will disable their capacity of a well succeeded performance if needed in a real fire situation. A planned test and maintenance approach must be ensured and test frequency accomplished in accordance to that planning. Concerning the establishment of test frequency there are some scientific approaches that can be used regarding each specific fire safety system. For the majority of the buildings this is the problem and the concerns about fire safety systems beyond the project phase.

\section{Acknowledgements}

None.

\section{Conflict of interest}

The author declares no conflict of interest.

\section{References}

1. Fontana M, Favre JP, Fetz C. A survey of 40.000 building fires in Switzerland. Fire Safety Journal. 1999;32:137-158.

2. Ramachandran G. Fire safety management and risk assessment. UK: MCB University Press; 1999. 17(9-10):363-376.

3. Dieken D. Inspection, Testing and Maintenance of Fire Protection Systems at Electric Generating Plants. Hartford Steam Boiler Inspection and Insurance $\mathrm{Co} ; 2015$.

4. Sobral J, Ferreira LA. Availability of fire pumping systems under periodic inspection. Journal of Building Engineering. 2016;8:285-291.

5. Hauptmanns U, Marx M, Grunbeck S. Availability analysis for a fixed wet sprinkler system. Fire Safety Journal. 2008;43:468-476.

6. Zio E. An Introduction to the Basics of Reliability and Risk Analysis, Series in Quality. Reliability and Engineering Statistics. 2007;13:236. 